\title{
Plasma Fibrinogen and Its Correlates in Children from a Biracial Community: The Bogalusa Heart Study
}

\author{
WEIHANG BAO, SATHANUR R. SRINIVASAN, AND GERALD S. BERENSON \\ Department of Applied Health Sciences, Tulane University Medical Center. School of Public Health and Tropical \\ Medicine, New Orleans, Louisiana 70112-2824
}

\begin{abstract}
Fibrinogen levels were measured in 5- to 17y-old children $(n=3047 ; 40 \%$ black and $49 \%$ female), from a well-defined biracial community. No significant race and sex differences in fibrinogen levels were observed, but levels increased $(p<0.001)$ with age or sexual maturation in black females. Adjusted for age, fibrinogen concentrations were positively correlated with ponderal index (weight/height $\left.{ }^{3}\right)(0.09-0.22, p<0.01)$, triceps skinfold thickness $(0.10-0.23, p<0.05)$, and subscapular skinfold thickness $(0.13-0.24, p<0.01)$ in all race-sex groups. Weak correlations were found between fibrinogen level and blood pressure and lipoprotein components for some of the race-sex groups, but these become nonsignificant or minimal after adjustment for ponderal index and skinfolds. A positive correlation $(0.12-0.16, p<0.01)$ was found between fibrinogen and white blood cell count for Caucasians, which still held after adjustment for ponderal index and skinfolds. In a stepwise regression, ponderal index, white blood cell count, and HDL cholesterol showed an independent association with fibrinogen. (Pediatr Res 33: 323 326, 1993)
\end{abstract}

Abbreviations

WBC, white blood cell count

Fibrinogen levels, involved in both blood clotting and the rheologic characteristic of blood flow (1-5), have been proposed as a cardiovascular risk factor variable; numerous studies (6-12) have shown a positive relationship between coronary heart disease and elevated fibrinogen levels. It has also been suggested (6, $13,14)$ that fibrinogen deposition may be one of the mechanisms leading to coronary atherosclerosis and coronary occlusion.

Although the relationships of fibrinogen to other coronary heart disease risk factors have been studied extensively in adults, information on children is limited. Observations from the Bogalusa Heart Study show that coronary atherosclerosis has a childhood onset $(15,16)$. Racial (black-Caucasian) differences in cardiovascular risk factor variables also occur in children. The objective of this study is to describe the distribution of plasma fibrinogen levels in children and to examine the association of fibrinogen with other cardiovascular risk factor variables.

Received August 4. 1992: accepted December 10, 1992.

Correspondence and reprint requests: Gerald S. Berenson, M.D., Tulane University Medical Center. School of Public Health \& Tropical Medicine, 1501 Canal Street, 14th Floor, New Orleans, LA 70112-2824.

Supported by funds from the National Heart, Lung, and Blood Institute of the U.S. Public Health Service (USPHS). Early Natural History of Arteriosclerosis 5R01 HL38844, and the National Center for Cardiovascular Health.

\section{MATERIALS AND METHODS}

Population. The study population is made up of children from Bogalusa, Iouisiana, a semirural, biracial ( $36 \%$ black, $64 \%$ Caucasian) community and surroundings with a defined population of approximately 22000 people. Demographic, health history, anthropometric, blood pressure, serum lipids and lipoproteins, nutrition, and biobehavior data were collected at various intervals from this population. During 1987-1988, a cross-sectional survey of children aged 5-17 y was conducted in which 3047 children, $40 \%$ black and $49 \%$ female, had fibrinogen levels measured. It was reported that 2610 of these individuals were fasted before screening.

General examinations. The details of the various aspects of the overall cardiovascular risk factor screening have been described previously $(15,16)$. In summary, this screening included a complete physical examination, anthropometric measurements, blood pressure determinations, estimation of sexual maturity with the Tanner Scale, and blood samples.

A health habits questionnaire was administered to obtain information including cigarette smoking (for subjects in the 3rd grade or higher), alcohol consumption (for subjects in the 7 th grade or higher), and oral contraceptive use by females (for those in the 7 th grade or higher). A subject was classified as a smoker or a drinker if he or she was an adopter or experimenter (17). During the survey, 2043 subjects completed (answered "yes" or "no") the questions for smoking, 2039 completed those for drinking, and 551 females completed those for oral contraceptive pill use.

A questionnaire for the presence of parental history of cardiovascular disease such as myocardial infarction, stroke, and diabetes mellitus was also obtained from parents of the study subjects.

Laboratory procedure. Hematologic data were determined using a Technicon H6000 (Technicon Instrument Corp., Tarrytown, NY). Plasma fibrinogen levels were determined using a method described by Swaim and Feders (18), a modification of the Jacobsson procedure (19). Serum total cholesterol and triglycerides were measured with a Technicon Auto Analyzer II (Technicon Instrument Corp.) according to the protocol developed by the Lipid Research Clinics Program (20). Serum VLDL, LDL, and HDL cholesterol fractions were analyzed by a combination of heparin-calcium precipitation and agar-agarose gel electrophoresis procedures (21).

Statistical analyses. The mean and standard error of fibrinogen were calculated for each age-, race-, and sex-specific group. Age or sexual maturation, race, and sex differences were studied in an analysis of covariance after examining the interactions. The effect of age or sexual maturation was also studied for each racesex group. The association of fibrinogen and obesity. blood pressure. or lipoprotein components were then inspected through Spearman correlation coefficients by race and sex adjusted for 
age. Fibrinogen levels were also compared between cigarette smokers and nonsmokers, alcohol users and nonusers, and oral contraceptive users and nonusers (females only), as well as between subjects with or without parental history of myocardial infarction, stroke, or diabetes mellitus. A stepwise regression was applied to determine the relative importance of the risk factor variables on fibrinogen concentration. Predictive variables were further examined through presenting levels for each quintile of fibrinogen. An increasing or decreasing linear trend was tested. adjusting for age and ponderal index (for blood pressure and lipoprotein cholesterols).

\section{RESULTS}

Fibrinogen levels. The mean and standard error are given in Table 1 for each age-race-sex group. Mean fibrinogen levels were compared between race and sex groups with and without controlling for age. No significant race or sex difference was found. Fibrinogen was found to increase significantly with age $(r=0.17$, $p=0.0001)$ or Tanner stage $(r=0.18, p<0.001)$ in black females only.

Correlations between fibrinogen levels and other cardiovascular risk factor variables. Figure 1 shows age-adjusted Spearman correlation coefficients between fibrinogen concentration and selected cardiovascular risk factor variables for each race-sex group. A positive correlation was observed between fibrinogen concentration and ponderal index $(0.09-0.22)$, triceps skinfolds $(0.10-0.23)$, and subscapular skinfolds $(0.13-0.24)$ in all race-sex groups. This correlation tended to be stronger in magnitude for Caucasian females. For some race-sex groups, positive correlation also existed between fibrinogen and blood pressure, LDL cholesterol, and VLDL cholesterol. These correlations were low in magnitude $(0.07-0.15)$ and became nonsignificant or minimally significant after adjustment for ponderal index and skinfolds. Similar observations apply to the negative correlation between fibrinogen and HDL cholesterol. Fibrinogen correlated positively with the WBC $(0.12-0.16)$ in females of both races and Caucasian males. This correlation still held after the adjustment for ponderal index and skinfolds.

Fibrinogen level was compared between cigarette smokers and nonsmokers, alcohol users and nonusers, and female oral contraceptive users and nonusers, as well as children with or without a positive parental history of myocardial infarction, stroke, or diabetes mellitus. No significant difference was found.

Relative predictability of these risk factor variables for fibrinogen was assessed in a stepwise multivariate regression. Independent variables used were height, ponderal index, systolic and diastolic blood pressure, VLDL cholesterol, LDL cholesterol, HDL cholesterol, WBC, cigarette smoking, alcohol use, and oral contraceptive use in girls. Significant predictors by each race-sex group are listed in Table 2. Generally, ponderal index, WBC, and HDL cholesterol had a stronger independent association with fibrinogen. However, variability explained by these independent variables only ranges from 3 to $9 \%$.

To detail the association between fibrinogen level and its predictive risk factors, Figure 2 provides the risk factor levels for each age group-specific quintile of fibrinogen. It is seen that ponderal index had a precipitous rise over the upper $40 \%$ rank- ings of fibrinogen. The linear trend of increase is significant $(p$ $\leq 0.001$ ) for all the race-sex groups.

HDL cholesterol decreased in Caucasian males $(p \leq 0.01)$. Caucasian females $(p=0.0001)$, and black females $(p \leq 0.001)$. Except for the lowest quintile of fibrinogen, WBC levels increaseed for males $(p<0.05)$ and Caucasian females $(p<0.01)$.

It is observed from Figure 2 that children with the highest fibrinogen concentration ( 5 th quintile) were more likely to show increases in other risk factors. Further analysis also showed this group to have a significantly higher prevalence of positive parental history for maternal diabetes mellitus (7.6 versus $5.4 \%$ ) and paternal hypertension (23.4 versus $17.9 \%)$.

\section{DISCUSSION}

This study demonstrated an interesting and consistent increase in fibrinogen levels with ponderal index and skinfolds in children. Also found were some positive associations of fibrinogen level with blood pressure, VLDL cholesterol, LDL cholesterol, and WBC and a negative association with HDL cholesterol. The positive correlations with obesity and WBC and negative association with HDL cholesterol were stronger than with other risk factors. The magnitudes of these correlations were generally low, as found in adult studies $(13,22,14)$ (approximately $0.1-0.2)$; however, these may not mean that fibrinogen is less predictive of cardiovascular disease than other risk factors $(23,24)$. Fibrinogen values did not differ essentially between blacks and Caucasians or males and females in our study, although an increase in levels with age or sexual maturation was noted in black females. In a large four-community study involving 12000 men and women aged 45-64 y, Folsom et al. (22) found that fibrinogen levels are higher in blacks than Caucasians and higher in females than males. Our current study suggests that fibrinogen increases earlier or to a greater extent for black females which results in the highest adulthood level seen in black females.

Epidemiologic studies in adults $(13,14,22,23)$ have shown the association between fibrinogen concentration and obesity, blood pressure, lipoprotein cholesterol, and WBC. The correlations were generally less than 0.3 and explained 10 to $20 \%$ of the variability of fibrinogen level. Our observation confirmed that similar associations also occur in children and adolescents. Among the risk factors selected, obesity index, WBC, and HDL cholesterol contributed significantly toward the prediction of fibrinogen level. Numerous indices reflecting obesity exist in the literature. Derived from weight and height, ponderal index (weight/height ${ }^{3}$ ) instead of quetelet index (weight $/$ height $^{2}$ ) was reported in the current study. For children, ponderal index is more independent of height than quetelet index $(r=-0.10$ versus $r=0.66)$, and it reflects both subscapular (central) and triceps (peripheral) skinfolds $(r=0.56,0.62)$ in the current data. It is of interest to see that even though ponderal index and subscapular and triceps skinfold thickness reflect somewhat different aspects of obesity their associations with fibrinogen were similar.

An increase by age in fibrinogen has been shown for adults (14, 22, 24-27). As reported by Lee et al. (14), based on 8824 subjects aged 40 to $60 \mathrm{y}$, older people had higher fibrinogen levels compared with younger people. In children, which we studied, this relationship to aging was only present for black

Table 1. Fibrinogen levels $(g / L)$ by age, race, and sex: the Bogalusa Heart Study

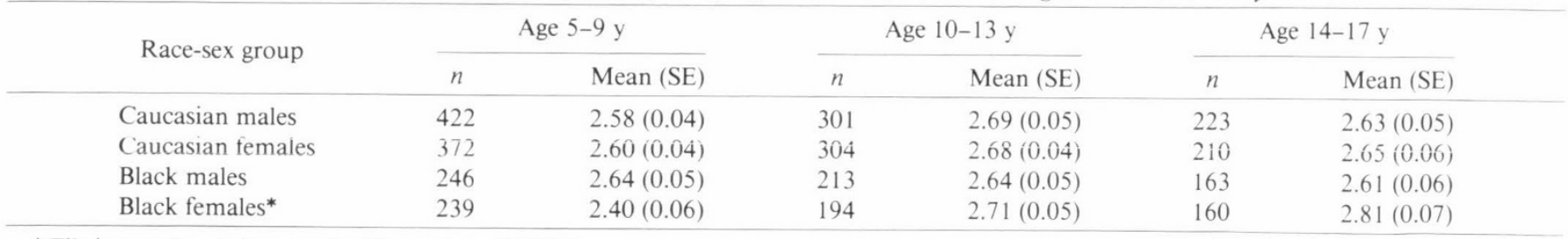

${ }^{*}$ Fibrinogen levels increased with age $(p=0.0001)$. 


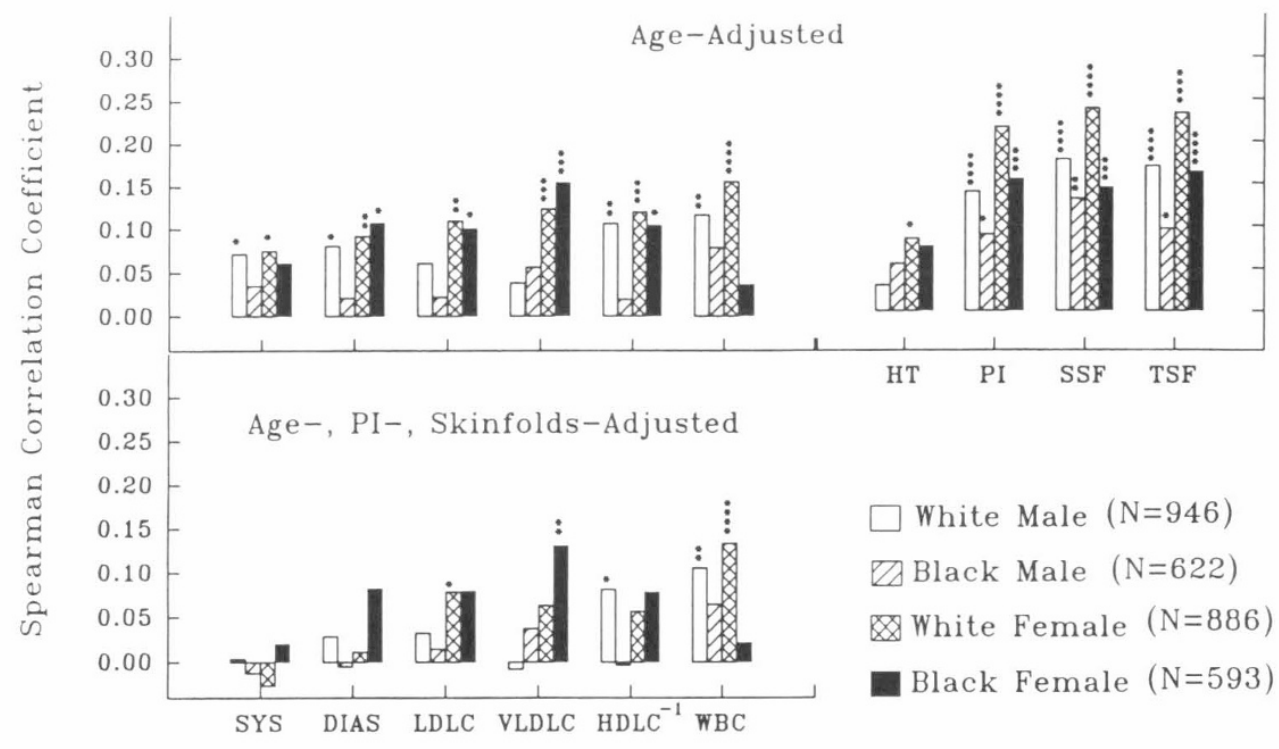

Risk Factor

${ }^{*} \mathrm{P}<0.05 ;{ }^{* *} \mathrm{P}<0.01 ;{ }^{* * *} \mathrm{P}<0.001 ;{ }^{* * * *} \mathrm{P}<0.0001$

Fig. 1. Age-adjusted race- and sex-specific Spearman correlation between fibrinogen concentration and height $(H T)$, ponderal index $(P I=$ weight/height ${ }^{3}$ ), subscapular skinfold thickness $(S S F)$, systolic and diastolic blood pressure ( $S Y S$ and DIAS), LDL, VLDL, and HDL cholesterol ( $L D L C, V L D L C$, and $H D L C$ ), and WBC from the Bogalusa Heart Study.

Table 2. Significant predictors of fibrinogen by race and sex: the Bogalusa Heart Study*

\begin{tabular}{|c|c|c|c|c|}
\hline & $\begin{array}{c}\text { Caucasian } \\
\text { males } \\
(n=905)\end{array}$ & $\begin{array}{c}\text { Caucasian } \\
\text { females } \\
(n=851)\end{array}$ & $\begin{array}{c}\text { Black } \\
\text { males } \\
(n=597)\end{array}$ & $\begin{array}{c}\text { Black } \\
\text { females } \\
(n=567)\end{array}$ \\
\hline & $\begin{array}{l}\text { PI } \\
- \text { HDL-C } \\
\text { WBC }\end{array}$ & $\begin{array}{l}\text { PI } \\
\text { WBC } \\
\text { Height } \\
\text { LDL-C }\end{array}$ & $\begin{array}{l}\text { PI } \\
\text { WBC }\end{array}$ & $\begin{array}{l}\text { Height } \\
\text { PI } \\
\text {-HDL-C }\end{array}$ \\
\hline$R^{2}$ & 0.0416 & 0.0903 & 0.0296 & 0.076 \\
\hline
\end{tabular}

${ }^{*}$ PI, ponderal index (weight/height ${ }^{3}$ ); HDL-C, HDL cholesterol; LDLC, LDL cholesterol.

females. Comparison of mean levels across different studies is often difficult because of the methodologic differences. Similariy, for males and females, children's fibrinogen levels in the current study were lower than the adults' levels in the Framingham Study (11) $(2.8-3.1 \mathrm{~g} / \mathrm{L}$ for adults aged $47-79 \mathrm{y})$ or the four-community study (22) (2.9-3.4 g/L) but higher than the adults' levels in the Scottish Heart Study (14) (2.2-2.5 g/L for adults aged 40-59 y). Some of these differences may be due to genetic factors (28).

Several studies $(14,22,29-31)$ demonstrated in adults that fibrinogen increases in smokers and decreases in drinkers. The relationships between fibrinogen and cigarette smoking or alcohol consumption were not seen in this study. Only a tendency of increased fibrinogen level was noted with smokers. A positive relationship between cigarette smoking and WBC and platelets was found in the Oslo Youth Study (32). The lack of significant associations between these risk factors and fibrinogen levels may be due to the low statistical power or to a shorter duration and lower intensity of smoking and alcohol consumption in childhood versus adulthood. This lack of statistical power may also result in no consistent association between levels of fibrinogen and oral contraceptive use.

Sugrue et al. (33) observed elevated fibrinogen levels in subjects with familial history of myocardial infarction, whereas others (34) did not confirm such a finding. In our study, no significant association was observed. The relationship between fibrinogen

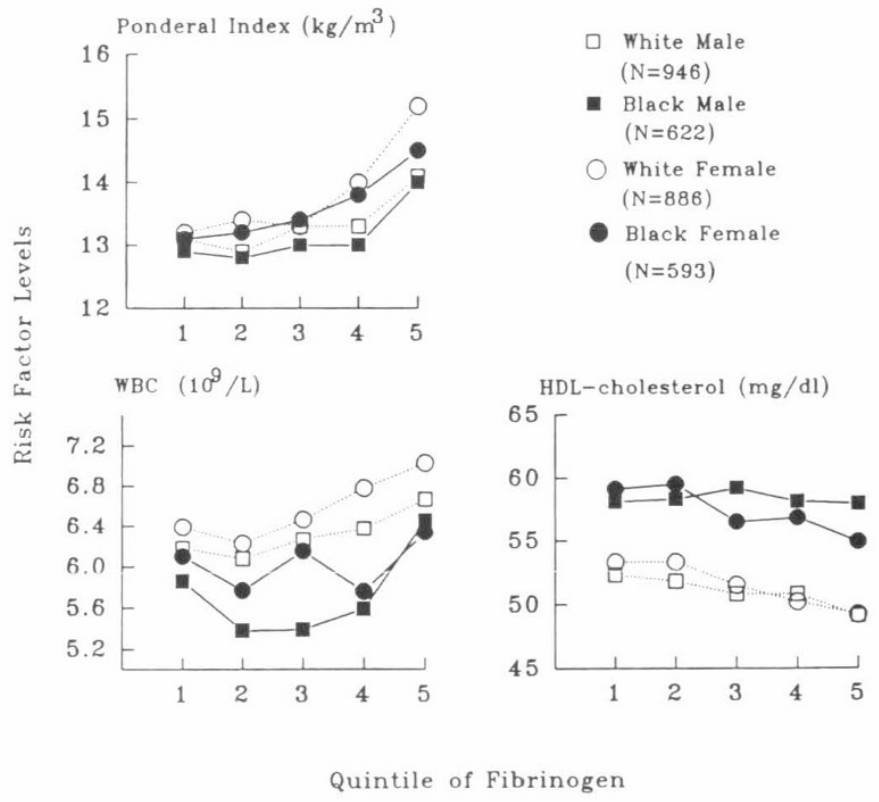

Fig. 2. Selected risk factor levels for age-group-specific quintiles of fibrinogen by race and sex. With fibrinogen level increased, ponderal index and WBC increased with an accelerating rate $(p \leq 0.001)$ and HDL cholesterol decreased $(p \leq 0.01)$ except for in black males. The $p$ values are the significance levels of linear trends. Ponderal index was compared after adjusting for age; WBC and HDL cholesterols were compared after adjusting for age and ponderal index.

and parental diabetes mellitus, as suggested by others $(35,36)$, was only found in children with the highest fibrinogen concentrations; the same was true of the relationship between fibrinogen and parental hypertension. The lack of significance may be due to the age of the parents, which was younger than the age at which clinical disease is manifest. Although family history is only a surrogate measure of cardiovascular disease, there may be important genetic and environmental implications underlying the familial aggregation of a high risk profile. 
Unlike in adults, in children the relationship of fibrinogen levels to myocardial infarction, stroke, and peripheral vascular disease cannot be determined. The pathophysiologic mechanisms of fibrinogen, through involvement in platelet aggregation, blood rheology, and endothelial cell injury, which play a key role in thrombosis and atherosclerosis, need to be further understood (37-43). However, because higher fibrinogen levels have been shown to have a positive relationship with coronary heart disease and other risk factors, these relationships may reflect on the thrombotic mechanism that is considered to contribute to arterial intimal atherosclerotic changes. The influence of childhood fibrinogen levels may also come from the potential "tracking" of childhood levels into adulthood. Obesity seems to have the strongest association with higher fibrinogen levels and is also a risk factor for peripheral thrombosis. This consistent relationship may also imply that the genetic factors that control obesity may also affect fibrinogen levels. Although methods are not established to control fibrinogen directly, control of other accepted risk factors $(23,44)$, such as weight control, exercise, diet management, and smoking cessation in adults, should apply to children as well. Because it is important to begin the prevention of atherosclerotic disease in early life, the factors that influence fibrinogen levels should also be considered, starting in childhood.

\section{REFERENCES}

1. Duguid JB 1976 The Dynamics of Atherosclerosis. Aberdeen University Press, Aberdeen, Scotland

2. Burch GE, Depasquale NP 1965 Hematocrit, viscosity and coronary blood flow. Dis Chest 48:225-232

3. Dintenfass L, Julian DG, Miller G 1966 Viscosity of blood in normal subjects and in patients suffering from coronary occlusion and arterial thrombosis. Am Heart J 71:587-600

4. Merrill EW 1969 Rheology of blood. Physiol Rev 49:863-887

5. Lowe GDO, Morrice JJ, Forbes CD, Barbenel JC 1979 Subcutaneous ancrod therapy in peripheral arterial disease: improvements in blood viscosity and nutritional flow. Angiology 30:594-599

6. Korsan-Bengtsen K, Wilhelmsen L, Tibblin G 1972 Blood coagulation and fibrinolysis in a random sample of 788 men 54 years old. II. Relations of the variables to "risk factors" for myocardial infarction. Thromb Diath Haemorrh 28:89-98

7. Wilhelmsen L, Svardsudd K, Korsan-Bengtsen K, Larsson B, Welin L, Tibblin G 1984 Fibrinogen as a risk factor for stroke and myocardial infarction. Fibrinogen and cardiovascular disease. N Engl J Med 311:501-505

8. Meade TW, Chakrabarti R, Haines AP, Stirling Y, Thompson SG 1980 Hemostatic function and cardiovascular death: early results of a prospective study. Lancet 1:1050-1053

9. Meade TW, Brozovic M, Chakrabarti RR, Haines AP, Imeson JD, Mellows S, Miller GJ, North WRS, Stirling Y, Thompson G 1986 Haemostatic function and ischaemic heart disease: principal results of the Northwick Park Heart Study. Lancet 2:533-537

10. Stone MC, Thorpe JM 1985 Plasma fibrinogen: a major coronary risk factor J R Coll Gen Pract 35:565-569

11. Kannel WB, Wolf PA, Castelli WP, D’Agostino RB 1987 Fibrinogen and risk of cardiovascular disease: The Framingham Study. JAMA 258:1183-1186

12. Mistry P, Chawla KP, Rai HP, Jaiswal P 1990 Plasma fibrinogen levels in stroke. J Postgrad Med 36:1-4

13. Balleisen L, Assmann G, Bailey J, Epping P-H, Schulte H, van de Loo J 1985 Epidemiological study on factor VII, factor VIII and fibrinogen in an industrial population. II. Baseline data on the relation to blood pressure, blood glucose, uric acid, and lipid fractions. Thromb Haemost 54:721-723

14. Lee AJ, Smith WC, Lowe GDO, Tunstall-Pedoe H 1990 Plasma fibrinogen and coronary risk factors: The Scottish Heart Health Study. J Clin Epidemiol 43:913-919

15. Berenson GS, McMahan CA, Voors AW, Webber LS, Srinivasan SR, Frank GC, Foster TA, Blonde CV 1980 Cardiovascular Risk Factors in Children:
The Early Natural History of Atherosclerosis and Essential Hypertension. Oxford University Press, New York

16. Berenson GS (ed) 1986 Causation of Cardiovascular Risk Factors in Children. Perspectives on Cardiovascular Risk in Early Life. Raven Press, New York

17. Hunter SM, Webber LS, Berenson GS 1980 Cigarette smoking and tobacco usage behavior in children and adolescents: The Bogalusa Heart Study. Prev Med 9:701-712

18. Swaim WR, Feders MB 1967 Fibrinogen assay. Clin Chem 13:1026-1028

19. Jacobsson K 1955 Studies on the determination of fibrinogen in human blood plasma. Scand J Clin Lab Invest 7(suppl 14):1-54

20. Lipid Research Clinics Program 1974 Manual of Laboratory Operations, Vol 1. Lipid and Lipoprotein Analysis. National Institutes of Health, Washington. DC. DHEW Publication No. (NIH) 75-628)

21. Srinivasan SR, Berenson GS 1983 Serum lipoproteins in children and methods for study. In: Lewis LA (ed) CRC Handbook of Electrophoresis, Vol III Lipoprotein Methodology and Human Studies. CRC Press, Boca Raton. FL. pp 185-204

22. Folsom AR, Wu KK, Davis CE, Conlan MG, Sorlie PD, Szklo M 1991 Population correlates of plasma fibrinogen and factor VII, putative cardiovascular risk factors. Atherosclerosis 91:191-205

23. Ernst E 1990 Plasma fibrinogen: an independent cardiovascular risk factor. J Intern Med 227:365-372

24. Kannel WB, D'Agostino RB, Belander AJ 1987 Fibrinogen, cigarette smoking. and risk of cardiovascular disease: insight from the Framingham Study. Progress in cardiology. Am Heart J 113:1006-1010

25. Hume R 1961 The relationship to age and cerebral vascular accidents of fibrin and fibrinolytic activity. J Clin Pathol 14:167-171

26. Moser KM, Hajjar CC 1966 Age and disease-related alterations in fibrinogeneuglobulin (fibrinolytic) behavior. Am J Med Sci 251:536-544

27. Meade TW, Chakrabarti R, Haines AP, North WRS, Stirling Y 1979 Characteristics affecting fibrinolytic activity and plasma fibrinogen concentrations. Br Med J [Clin Res] 20:153-156

28. Hamsten A, Faire U, Iselius L, Blomback M 1987 Genetic and cultural inheritance of plasma fibrinogen concentration. Lancet 2:988-990

29. Berglund U, Wallentin L, von Schenck H 1988 Platelet function and plasma fibrinogen and their relations to gender, smoking habits, obesity and betablocker treatment in young survivors of myocardial infarction. Thromb Haemost 60:21-24

30. Ogston D, Bennett NB, Ogston CM 1970 The influence of cigarette smoking on the plasma fibrinogen concentration. Atherosclerosis 11:349-352

31. Dobson AJ, Alexander HM, Heller RF, Lloyd DM 1991 Passive smoking and the risk of heart attack or coronary death. Med J Aust 154:793-797

32. Tell GS, Grimm RH Jr, Vellar OD, Theodorsen L 1985 The relationship of white cell count, platelet count, and hematocrit to cigarette smoking in adolescents: The Oslo Youth Study. Circulation 72:971-974

33. Sugrue DD, Trayner I, Thompson GR, Vere VJ, Imeson JD. Stirling Y, Meade TW 1985 Coronary artery disease and haemostatic variables in heterozygous familial hypercholesterolemia. Br Heart J 53:265-268

34. Jay RH, McCarthy SN, Rampling MW, Betteridge DJ 1991 Blood rheology and fibrinogen in children with familial hypercholesterolemia. Atherosclerosis $91: 117-121$

35. Lowe GDO, Drummond MM, Forbes CD, Barbenel JC 1980 Increased blood viscosity in young women using oral contraceptives. Am J Obstet Gynecol 137:840-842

36. Kannel WB, Wilson PWF, Zhang T-J 1991 The epidemiology of impaired glucose tolerance and hypertension. Am Heart J 121:1268-1273

37. Ross R 1986 The pathogenesis of atherosclerosis. An update. N Engl J Med $314: 488-500$

38. Lowe GDO 1986 Blood rheology in arterial disease. Clin Sci 71:137-146

39. Smith EB 1986 Fibrinogen, fibrin and fibrin degradation products in relation to atherosclerosis. Clin Haematol 15:355-370

40. Minno GD, Mancini M 1990 Measuring plasma fibrinogen to predict stroke and myocardial infarction. Arteriosclerosis 10:1-7

41. Packham MA, Mustard JF 1986 The role of platelets in the development and complications of atherosclerosis. Semin Haematol 23.8-26

42. Coccheri S 1991 Indici di rischio per la malattia aterotrombotica: i fattori della coagulazione. 1991 Ann Ital Med Int 6:408-415

43. Koenig W, Ernst E 1992 The possible role of hemorheology in atherothrombogenesis. Atherosclerosis 94:93-107

44. Ernst E 1991 Fibrinogen: a "new" cardiovascular risk factor. Fibrinogen: ein "neuer" kardiovaskularer Risikofaktor. Wein Med Wochenschr 141:375382 